\title{
PERSONALITY CHANGES AFTER OPERATIONS ON THE CINGULATE GYRUS IN MAN
}

\author{
BY
}

\author{
P. MACDONALD TOW and C. W. M. WHITTY \\ From the Nuffield Department of Surgery, University of Oxford, and the \\ Department of Neurology, Radcliffe Infirmary, Oxford
}

The use of anterior cingulectomy in the treatment of certain mental disorders gave us the opportunity of studying in a small group of patients, whose basic personality was unaffected by their illness, the changes which may follow lesions of this area. This paper is concerned with a report of six such cases.

The effect of lesions of the cingulate gyrus in animals has recently been described. Electrical stimulation of the area by Smith (1945), and ablation in monkeys by Ward (1948a and b) and by Glees, Cole, Whitty, and Cairns (1950) all resulted in striking transient changes in affective behaviour. It seemed desirable therefore to explore the possible therapeutic effects in man of an operation designed to remove a part of this small region.

Accordingly in 1948, the late Sir Hugh Cairns started operating on some chronic, severely disturbed mental hospital patients. The long-term results in such patients are reported elsewhere (Tow and Armstrong, 1953). In all cases there were significant changes in behaviour early after operation. There was evidence, both somatic and psychological, of lessened tension, amounting for a time to apathy and indifference. Negativism and aggressive outbursts were reduced, and patients who had appeared inaccessible for years responded again to their environment. Though mostly transient, these early changes in deteriorated patients were considered to justify a trial of the operation in selected patients with a basically well preserved personality suffering from severe, prolonged, and disabling psychiatric illness. Of these, two were unimproved by the operation, and had a standard leucotomy some nine months later. They are therefore only briefly mentioned. The other six have been observed for periods of three to four years since operation, and the personality changes noted form the basis of this report. Although clinical improvement resulted in all six cases, we are not concerned primarily with therapeutic results. These have already been described briefly (Whitty, Duffield, Tow, and Cairns, 1952), and we here attempt to describe the changes that occurred after operation, in the hope that they may illustrate some functions of the cingulate gyrus in normal cerebral economy, and thereby suggest therapeutic possibilities and limitations in individual cases of mental disorder.

Our information was collected not only from intensive study of the patients themselves, but also by personal interviews with near relatives, friends, and employers. By crude clinical standards the psychological changes are not great ; but even witho the few cases so far studied in detail there seem tod be certain constant and interesting alterations iri 을 personality.

\section{Extent of Lesion and Operative Technique}

Details of the operation have already bee reported (Whitty and others, 1952). It consists of bilateral suction-ablation of the major part of the anterior cingulate gyrus (Area 24 of Brodmann). The anterior limit of the excision lies immediately above the anterior edge of the genu of the corpus callosum. It measures about $1 \mathrm{~cm}$. in depth, $1 \mathrm{~cm}$. in breadth, and extends caudally for about $3 \mathrm{~cm}$. Some $3 \mathrm{~g}$. of cerebral tissue is removed (Fig. 1).

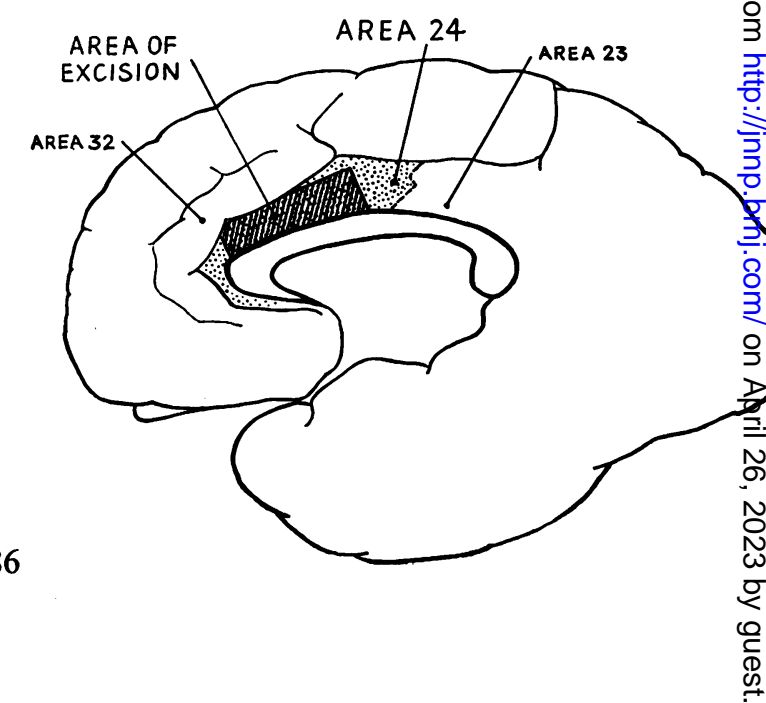


The operation is often technically difficult owing mainly to the proximity of the anterior cerebral arteries and their branches, which have to be preserved. There may be associated damage to other parts of the frontal lobe, secondary to ligation of vessels where this is necessary, but every effort is made to limit the lesion strictly to the area defined.

It should be emphasized that the use in these cases of precise anatomical terms, such as Area 24 or cingulate gyrus, are largely for convenience in describing the intended site of a lesion. Full necropsy studies in each case are essential for an exact assessment of an individual lesion. The postmortem appearances in three cases, not in this series, suggest that macroscopic damage was in fact limited to the medial aspect of the hemisphere as intended. Even though detailed histological study may reveal more widespread changes, the lesions discussed here are likely to be causing a more limited and well defined interference with the cortex of the inner aspect of the hemisphere than is the case in any "blind" fibre-cutting procedure.

\section{Case Records}

The following case summaries illustrate briefly the type of change we have noted.

Case 1 (R. I. No. 112542/49). - A married woman aged 29 at operation had had no psychiatric symptoms until, following the birth of three children in a matter of four years, she was left to try and bring them up in a small flat during the London blitz with her husband away in the army. She became irritable and depressed, and after an induced abortion, about which she felt very guilty, depressive symptoms with suicidal feelings were so severe that she entered a mental hospital as a voluntary. patient. She was discharged after a few months, very little improved by electro-convulsion therapy (E.C.T.). During the next four years, although only in hospital for short periods, she remained severely disabled-tense, anxious, and depressed, with episodes of acute panic, occasional suicidal feelings, and one suicidal attempt. Electro-convulsion therapy, modified insulin and continuous narcosis gave only temporary improvement. She was never able to take charge of her children who were boarded out. She remained intellectually clear and was so distressed by her symptoms that she willingly accepted any treatment offered, and four and a half years after the onset of her illness she was referred for cingulectomy.

At operation, on the left side the ablation had to be done in two parts with a bridge of tissue left where the anterior cerebral artery arched up on to the cingulate gyrus. However, on both sides the ablation was $3-4 \mathrm{~cm}$. long and to a depth of $1 \mathrm{~cm}$.

Following operation there was marked reduction in tension and distress. Her acute anxiety and panic states were abolished. A noticeable emotional flattening occurred at first, but this cleared gradually in about 10 days without any return of tension or anxiety. Six weeks after operation she returned home and shortly took charge of her children again. Her improvement was maintained, although on two occasions she became temporarily depressed, and six months later she regarded herself as virtually cured. She has now remained symptom free for nearly four years, managing her own house and family, as well as going out two mornings a week to do outside domestic work.

Her basic personality before the illness was somewhat rigid and inhibited. She kept to herself, made few friends, and found social intercourse difficult. Sexually she was cold, and said she submitted to intercourse for her husband's sake. In her private opinions and behaviour she was somewhat dogmatic and unyielding, and showed many minor obsessive traits. She had a strong sense of responsibility. Any demands for a lessening of her high standards of conduct produced obsessive ruminations and secondary anxiety about the consequences, though not of pathological intensity. Her judgment in household matters was sound, though she occasionally indulged in rather reckless spending which she afterwards regretted. She was brought up an Irish Protestant, but showed no special concern for religion or religious observance. She was vaguely interested in music, but had no marked artistic abilities or interests. Her sense of humour was limited.

After operation she showed definite personality changes. She was less shy and sensitive, mixed more readily, and discussed her feelings with less reserve. She became irritated and angry more easily, but these outbursts passed more quickly and she no longer brooded on incidents. She was less unyielding in her opinions and was prepared to consider them mistaken. She no longer worried so much over the possible consequences of some line of action she considered wrong. However, there was no lowering of her usual standards of cleanliness and tidiness in managing the house and children, but her obsessive traits in these and other matters had gone. She drove herself less hard and would not sacrifice herself so much for her family. Sexually she appeared unchanged. Her judgment was unimpaired. She had had no spending outbursts since operation. These changes were only noted by those who knew her intimately and were not considered a disadvantage. On the contrary, her husband considered she was in some ways better than before operation-steadier, more balanced, and not so easily upset by the demands of life.

Case 2 (R. I. No. 105523/46). - A married woman aged 38 at operation had suffered since the age of 15 from obsessive ruminations and attacks of depression. Distorted information she had gleaned on the subject of conception caused her to dwell continually on the morbidness and wickedness of the sex act. Even two things touching would upset her. These ruminations pervaded her mind so much that at times she would become unable to do any of her household duties and would remain shut in her room and often in bed. Always subject to swings of mood she had periods of depression with feelings of guilt and un- 
worthiness, when the ruminations became more intense. She could not enjoy sexual intercourse, though at times desire was intense. She had sought psychiatric advice as an out-patient on several occasions, and shortly after the birth of her second child, when she was 35 , there was an acute exacerbation and she was admitted to a mental hospital. At this time she was tense, agitated, and confused, pouring forth a stream of semi-coherent talk on sex and religion. She improved with E.C.T. sufficiently to return home, but despite further E.C.T. to a total of 60 shocks, she remained severely ill for the next three years. Her household was neglected and her children cared for by relations. She could only sleep with heavy doses of barbiturates, and spent much of her time in bed or huddled in a corner of her room. Her intellect was well preserved and her clear insight added to her distress. Cingulectomy was performed at this stage.

At operation, on the right, the ablation extended to the upper part of the genu, about $3 \mathrm{~cm}$. long and $1 \mathrm{~cm}$. deep; on the left it was as long but not so deep. A cortical vein draining to the sagittal sinus on the right was divided.

Following operation her tension and distress were at once reduced. The ruminations still occurred but she could now dismiss them and turn her attention elsewhere. During the first few days she was occasionally incontinent of urine, and two weeks after operation she had two major epileptic fits, but none thereafter. During the next six months her ruminations steadily decreased in intensity. On one or two occasions, especially when some financial worries were prominent, they increased temporarily. However, within a year from operation she was entirely free from her morbid thoughts, and was managing her house and children in a relaxed and cheerful frame of mind. This position has been maintained for four years.

As a girl she had always been regarded as shy, selfcontained, rather over-meticulous, and conscientious. She had had a strict religious upbringing, and continued to take an active interest in religion when her illness permitted. After its onset, at times when her symptoms were slight, her basic personality emerged clearly enough. She did not mix readily or express her feelings, but inwardly she was dogmatic and rigid in her views. She exacted high standards of herself and expected them of others. Although basically friendly and affectionate, these traits were often obscured by her insistence on self-discipline. She read widely and played the piano and violin well, but " could not tolerate rubbish" either in books or music.

After operation her personality showed some change. She expressed her feelings more freely, would enjoy playing with the children more, but would be more easily irritated and show it at once. She mixed more readily and would discuss her personal affairs with friends as she would not previously. She worried less over the misfortunes of others. She was as efficient and tidy in the house as before, but was less insistent that everything must be just right. She demanded less of herself and others. Her emotional responses were more spontaneous but more quickly over. She read less and then only light literature. Her piano playing was also now only of light popular tunes and improvisations. Her sense of humour was broader. She retained her religious convictions, but was less regular in religious observances. Her husband thought her less prone to put his and the children's interests before her own. However, most of the family and intimate friends considered she was improved by being less fussy and more ready to take things as they came.

Case 3 (R. I. No. 110696/49). - A married man, aged 44 at operation, had been free from psychiatric symptoms until, at the age of 35 , while serving with the R.A.F. as a corporal in the western desert, he began to be increasingly irritable and unable to concentrate or make decisions. He could not eat or sleep properly, and became so depressed and anxious that he was sent to a military mental hospital, where continuous narcosis and modified insulin were given with no improvement, and he was invalided from the service. He considered this a severe disgrace, which added to his distress. For the next eight years he remained tense, anxious, and depressed. He developed obsessional symptoms with some ritualistic behaviour. He attended the psychiatric out-patient department, but doggedly refused to enter hospital. He could not sleep without sedatives, and had to take barbiturates by day also. He lost much weight. He managed to carry on with clerical work, but his efficiency was greatly reduced. His insight was well preserved which added to his distress. At last he felt $\frac{\rho}{\mathbb{D}}$ he could carry on no longer, and cingulectomy was $\varrho-$ decided on some 10 years after the onset of his illness.

At operation several fine veins right down in the $\Omega$ ํㅡㄹ cingulate region were divided to get adequate exposure. Lesions of $3 \mathrm{~cm}$. by $1 \mathrm{~cm}$. were made on each side. Some fibres of the cingulum were probably involved. A tiny artery running across the right cingulate gyrus was: divided.

After operation his tension was reduced. He lost his anxiety, restlessness, and depression, and his obsessional symptoms cleared. For a few weeks his mood was slightly euphoric. He returned home within five weeks. At this time he was cheerful and free from anxiety. $\mathrm{He}$ ate well and regained his normal weight. He continued to take sedatives at night and slept well, but required none by day. He returned to work as a salesman, and for some months did well. However, he readily became flustered in any unusual situation, and, because of complaints of rudeness to customers, he lost his job. This produced a resentful, almost paranoid attitude, and although he got other work, some of this attitude persisted. Three and a half years later he was free from anxiety and depression, had none of his previous restlessness, or obsessions. He was occasionally depressed for short periods, but never so intensely as before operation. He continued to blame the employers who had dismissed him for what symptoms he still had.

His pre-morbid personality showed a precise, meticulous, very conscientious man. He took endless trouble to do things exactly right, and was fussy over personal appearance, cleanliness, and general tidiness. He was 
reserved, and did not mix well and centred his interests in his family, to whom he had a marked sense of responsibility. He was never demonstratively affectionate, and was sexually rather cold. He had considerable energy and drive, and did very well as an insurance salesman. He was a keen gardener and had a workshop in which he did woodwork. In his private opinions, he was dogmatic and obstinate, though he would not express his feelings outside his immediate circle. His sense of humour was limited, which further reduced his social contacts. In business and general matters his judgment was sound, and he would consider almost too carefully every aspect of a problem. He had no strong religious convictions.

Following operation he was less reserved. He expressed his feelings more freely, and would show impatience and irritability more readily, though these would be short-lived. Though still precise, neat, and tidy, he would no longer insist on doing things so thoroughly, and would not worry over details, or consider problems from every angle. In consequence his judgment seemed slightly impaired at times. He showed a definite reduction in energy, tired rather easily, and took much less interest in his hobbies. These changes were shown also in his work, though here a more marked effect was his impatience at interruptions and consequent abruptness to customers or business seniors which was responsible for his losing his first post-operative job. His interest in his family was maintained, and sexually he was unchanged. His wife thought him substantially the same as he had always been, though she noticed especially his reduced energy and drive. Some of his friends thought him improved, less stiff and easier to get on with. His less inhibited behaviour undoubtedly allowed a slightly paranoid trend to emerge, and this was clearly seen in his reaction to his loss of work.

Case 4 (R. I. 33964/44). - A single woman, aged 26 at operation, had always been sensitive, shy, and prone to worry over trifles. However, florid psychiatric symptoms had not become marked until she took her first job at the age of 15 . She then began to evolve ritualistic behaviour involving folding her clothes in a special way, and placing a needle and pin in a special position beside her bed. Failure to carry these out would cause intense anxiety. Fear of anything connected with death became obsessive and she had to give up her job because she came to believe that someone had committed suicide in the firm's lavatory. Her rituals and anxieties became so involved and incapacitating that she entered a mental hospital as a voluntary patient at the age of 20 . During the next two years she was in and out of hospital and had E.C.T., continuous narcosis, and modified insulin treatment. Improvement with these was short-lived, and frontal leucotomy was finally performed. Improvement followed, and for some months her rituals were abandoned. She became less tense and anxious and her obsessions about death cleared. She returned to clerical work. However, within a year, her symptoms had returned and were as severe as ever. E.C.T. gave no relief, and she returned to hospital and to a "disturbed" ward. She was tense and at times panic-stricken, and was withdrawn and unresponsive, at times refusing food and drink. She had been like this for nearly two years when cingulectomy was undertaken.

At operation, in the approach to area 24 three small veins going to the sagittal sinus had to be divided. The area of removal was small but the cingulum was probably involved on both sides. Ablations were just over $0.7 \mathrm{~cm}$. in width and just over $1 \mathrm{~cm}$. long, that on the right being more posterior.

Following operation, she again improved. Her tension and anxiety were relieved. There was no further ritualistic behaviour. She returned home in two months, and picked up many interests and hobbies she had not done for years. She established a firm friendship with a younger woman whom she had met while in hospital, and this seemed a factor in consolidating her recovery. There was a brief period of return of depression, but without rituals or obsessions, and this soon cleared. Six months after operation she was busy and happy at home, and taking a normal part in social life at clubs and dances. This position was maintained three years later.

Assessment of personality change after cingulectomy was complicated by the earlier leucotomy. Before her illness developed fully she was a shy, retiring person who found it difficult to mix and make friends and would never express her feelings readily. She was mildly obsessional about cleanliness and had always been preoccupied with thoughts of death. She would often worry intensely over whether she was behaving correctly. She was credulous and rather easily led, and had never had much drive or energy. Following leucotomy she was for a time more forthcoming and mixed more easily in company. She worried less about what others thought of her. However, these changes were soon submerged again by her symptoms.

After cingulectomy the most striking change was her greater sociability. With this went a more care-free attitude and a greater readiness to express her feelings, both in confidences to her friends, and in a show of irritation or impatience at what annoyed her. She showed an increased independence of her family, and was less timid and shy. She would no longer brood over things, and was not especially concerned as to whether she was doing "the right thing". She had no special intellectual or artistic interests either before or after operation. Her obsessive thoughts about death cleared completely, though she was still very insistent about personal cleanliness and tidiness. She seemed to tire and lose interest more easily. She certainly made no great effort to get work, but was content simply to help at home.

Case 5 (R. I. No. 103761/49). - A man aged 35 at operation had been free from psychiatric symptoms until after he was a prisoner of war in Japanese hands during the war. While working on the Thailand railway under notoriously bad conditions he began to imagine a smell from his genitals. On repatriation after the war, this idea persisted. Previously a skilled factory worker, he took work as a farm labourer in the hope that the open 
air would dispel the smell. At this time he set up house with a married woman by whom he had two children. He continued to worry about his smell and gradually his whole life became disorganized by this obsession. He bathed frequently and would only put his trousers on just before going to work. He would use no form of public transport and would never enter a public house or cinema for fear that people would smell him. He begged his doctor to arrange an operation for removal of his genitals. He became severely depressed and made an unsuccessful suicidal attempt. He was tense, unable to sleep, lost weight, and was subject to violent outbursts of temper. At times he dared not go to work, but remained shut in his bedroom. During four years he had much out-patient psychiatric treatment and continuous narcosis during a brief hospital admission. At this stage a cingulectomy was undertaken.

At operation on the left, a deep lesion was made by suction. A small vessel was coagulated and the total length of ablation was almost $3 \mathrm{~cm}$. On the right, the excision was broken up, an unusual mass being encountered in the middle of the lower part of the gyrus which was probably a small thrombosed aneurysm. On each side some fibres of the cingulum were involved.

Following operation he was greatly improved. His tension and depression cleared. Within a few weeks he returned home. Although when asked directly he said the smell was there at times, it no longer worried him. He resumed work and did overtime at potato harvest. He would visit his local public house and occasionally travelled on a bus. Six months later his depression returned briefly and he again avoided company for a while. However, this was short lived and he did not give up work, nor did he complain spontaneously of his smell. Since then he has remained normally cheerful, working regularly, and mixing freely. If asked directly he will say the smell is occasionally present, but in fact it no longer appears to influence his conduct at all. This was the position three and a half years after operation.

Before his illness he was a cheerful, even-tempered man, who got on well with his friends and family. Somewhat stolid and without ambition, he did not mix much and kept his feelings and opinions to himself. Although not unduly sensitive, he liked to feel in agreement with those around him, and would feel uncomfortable at doing anything out of the ordinary. He was careful of his personal appearance, tidy and methodical, but showed no obsessive traits. He had no interest in women and had never had sexual intercourse. He was a good footballer, both playing himself and following the game keenly. He had no intellectual or artistic pursuits and was not interested in religion.

After operation he mixed more freely and was more ready to express his feelings, though his affect was generally rather flatter. He was easily moved to irritation, though this passed quickly, and he no longer had any outbursts of violent temper. He tired more easily and never evinced any interest in football. He no longer seemed troubled about what others thought of him and was quite unconcerned at doing things which might cause comment. He spoke quite openly for instance about not being married to his "wife". Though still neat in personal appearance, he was less tidy and methodical. His general judgment and memory were unimpaired, but he found an increased difficulty in learning new skills and was slower at his work. He spent much time in playing with the children, though their noise would easily upset him and he would flare up momentarily.

Case 6 (R. I. No. 120998/50). - A man aged 40 at operation had been healthy, mentally and physically, $\mathscr{G}$ until the war, when, after three years of considerable $\overline{0}$ stress as an A.R.P. worker, he became tense, depressed, and unable to sleep. He suffered from headaches and many other bizarre bodily symptoms about which he formed hypochondriacal ideas which became very obsessive. He lost much weight. His normal drive and energy deserted him and his tension, anxiety, and obsessions about his bodily health became so severe that he had to give up work. He had two courses of E.C.T. and was admitted to a mental hospital for a period of continuous narcosis. These procedures gave temporary improvement. However, symptoms again became disabling. Headaches were very severe and would occur daily, and various " pains" in the abdomen and chest occurred. All these were matters of obsessional rumination to him and he was extremely tense and anxious thinking them evidence of grave organic disease. Furthe@ treatment, including E.C.T., brought no relief, ang cingulectomy was undertaken some six years after the onset of symptoms.

At operation the approach was difficult owing adhesions between the hemispheres. At first a lesion w\& made too far forward in the sub-callosal part of area on the right. Definition of the genu of the corpus of callosum then allowed bilateral cingulate lesions, about $4 \mathrm{~cm}$. long and deeper on the left than the right, to be made. On the left, the cingulum was involved.

After operation tension and anxiety were reduced. He complained less of his bodily symptoms, though if asked directly he said he still had them. He soon began to sleep better, and regained weight. After returning home in a few weeks his obsessional hypochondriasis and tension entirely cleared. However, he found many excuses for not taking up regular work for a considerable time, and for some months would have transient periods of mild depression. A year after operation these seemed to have cleared, and he was back at work free of symptoms, and this was the position two years later.

His premorbid personality showed a man who was continually pushing himself to excel in any activity he undertook. He appeared to be full of drive and energy. O He would mix well and was a member of many clubs and societies. He was always regarded as a leader and dare- 9 devil, and felt he must live up to this reputation. He was sensitive to what others thought of him and could not bear to be unpopular. He accepted the views and opinions of his set, and did not form his own much. He $\mathrm{N}$ was a keen athlete and good at tennis, cricket, and football. He was not specially active sexually, and after 
developing a hydrocele he became impotent for a time. $\mathrm{He}$ had no intellectual or artistic interests. He was a Roman Catholic, married to a Protestant, and though not overtly devout, he insisted on the children attending Mass regularly.

After operation he. no longer felt the urge to excel and to live up to a reputation. He was quieter in manner, and others said, " $\mathrm{He}$ is no longer the life and soul of the party". His energy and drive were lessened and for a time his performance at games fell off. He mixed as well and was as cheerful as before, but no longer felt worried about what others thought of him. He would become irritated with minor frustrations, and show it immediately. He seemed more self-centred. His sexual behaviour was unchanged. He was as affectionate as before, but might quarrel with his wife in public over some minor point, which he would not have done before. His affect seemed slightly shallower. His religious attitude was essentially unchanged, though he was less insistent about the children's religious upbringing. He made no real effort to start work again for several months after operation, although this was in a family business and quite easy to arrange.

Case 7 (R. I. No. 106422/49). -A married woman aged 49 at operation had a strong family history of depressive illness. She herself suffered occasional attacks of depression from 20 to 28 years of age. At 29, after the birth of her first child, she became severely depressed and obsessed by noises in her head and other bodily symptoms, and entered a mental hospital as a voluntary patient. She left after nine months slightly improved. Her symptoms continued though she managed to stay at home and do her housework until she was 47 . She then became tense and depressed with suicidal feelings and so troubled by compulsive thoughts that she again entered hospital as a voluntary patient. Electroconvulsive therapy and "somnifaine" narcosis produced no improvement, and after two years of severe illness, as her personality seemed well preserved, cingulectomy was done.

At operation, a group of veins from the convex surface of the right frontal pole had to be divided, and the removal on this side was about $3.5 \mathrm{~cm}$. long. On the left, the ablation was of the same size but was done in three pieces to avoid damage to the branches of the callosomarginal artery.

After operation she was much less tense. Her depression was reduced, and her obsessive thoughts and hypochondriacal symptoms were markedly improved for a few weeks. She went home, but already her symptoms were returning. Three months later she returned to hospital. It was noted then that she would talk about her symptoms and could be led on to other topics more readily than on her previous admission, and her signs of tension and distress would then lighten. Otherwise she was as before operation. Her condition was unaffected by narcosis and E.C.T. and six months later she had a leucotomy. Some months after, she was sufficiently improved to return home, and she has remained there since.

Her personality traits cannot be readily separated from her depressive symptoms, but she appears to have been a rather obsessive, meticulous woman, prone to worry about trivial things. She enjoyed company though she did not like being conspicuous and was regarded as shy. She was kind and sympathetic, but sexually rather cold. She had no interests beyond her house and family and was not a religious woman.

During the short period after cingulectomy, before her symptoms again obscured the picture, the only change clearly noticed was an increased readiness to express her feelings. There was some suggestion also that she worried less over matters arising from her environment.

Case 8 (R. I. No. 69251/47). - A woman aged 29 at operation was an illegitimate child, and herself married because already pregnant. She was free from psychiatric symptoms until after the birth of her second child. She then became hostile to her husband with some reason, and to her mother with no reason. She expressed delusions of persecution and reference, and periods of abnormal apathy would alternate with sudden rather inappropriate activity. During the next few years her paranoid ideas increased : and she was in hospital continuously for two years before cingulectomy. Here she accused the staff of sexual assault and was uncooperative and at times suddenly aggressive, though apart from her delusions she remained intellectually well preserved.

At operation, on the right, the lesion was $2.8 \mathrm{~cm}$. long. On the left it was slightly shorter. Lesions were deeper than usual, but on each side a small bridge of tissue was left beneath the origin of the calloso-marginal artery.

After operation she was much quieter, more cooperative, and made no further attacks on the staff. However, her delusions that men assaulted her during sleep remained and she thought she was pregnant, though these views now only emerged on questioning her. She then began to refuse food and drink because it would poison her, and as her paranoid ideas seemed completely unchanged, in view of the prognosis, leucotomy was done some eight months after cingulectomy. This resulted in improvement in behaviour and a gradual subsidence of her delusions. Some months later she was able to return home and has since remained there and is now doing clerical work, though clearly showing some of the features of frontal lobe deficit.

Her pre-morbid personality showed a self-reliant and opinionated woman, who did not care what others thought of her. She disliked authority and thought many conventions stupid. She never showed affection readily, though she kept up with two or three school-day friends. She married her husband because she was pregnant by him, but had only had intercourse at his urging and was in fact somewhat cold sexually. She was ambitious and eager to get on in life.

The brief period of observation following cingulectomy showed only a reduction in her tension and drive, with a tendency to express her opinions either delusional or otherwise only when asked about them. This reduced conation was also shown in her acceptance of hospital clothing and occupational therapy, which she had 
strenuously refused before. Her hostility to her husband remained unchanged, though her likes and dislikes of hospital staff, previously fairly constant, now changed from day to day.

\section{Discussion}

Our most important overall observation is that there has been little change in the total personality picture in these patients compared to the marked but transient behaviour changes seen in monkeys. In contrast also to what we can detect after a frontal leucotomy, although alterations occur in both instances in the sphere of social behaviour, the anterior cingulate subject shows nothing obviously unusual in his behaviour when one sees him, meets him, or talks to him : to all intents and purposes he is normal. It is important from the point of view of the clinician to stress this general impression as a background for the changes described.

A fairly clear-cut, composite picture can be drawn from the brief case histories given above. Although some subjects become unduly tired in the afternoon, capacity for work and actual level of performance seem unimpaired. Indeed, the only constant change here is an increase in the efficiency of certain activities related to the removal of an incapacitating symptom of the illness. Most subjects are considerably less meticulous in habits, and some are slower in thought and action. Judgment seems to be impaired at times in personal and social relations, but when confronted with concrete objects or situations the power of discrimination is not affected. In the intellectual sphere there appears to be a general slowing up and some lowering of comprehension not yet analysed. There is no evidence of any impairment of remote or recent memory.

Outside the narrower sphere of daily work there is a slight loss of depth and variety in general interests and pursuits, the nature of which depends on the subject's pre-operative level. There seems also less energy available for these activities. One who read widely in good literature now only sporadically reads much less worth-while books ; while another who read a large variety of good novels now reads much less avidly, and then only the poorer light magazines. One has given up his carpentry, gardening, and reading entirely. Both he and another have lost all interest in sport and now never go to football matches as they used to.

In the sphere of religious activity and thought, though we have watched closely for signs of change, we are unable to be sure of any real alteration in attitude.

In the general affective and instinctive life there are no very positive changes. Probably the affect is shallower, but not to any ordinary clinical degree.
Sexual activity does not seem to be altered beyond any fluctuation which can be attributed to the illness. Sexual desire is unchanged, but there is a of change in attitude to sex, and in talking about it, $\underset{\overrightarrow{0}}{\bar{a}}$ which is freer and more uninhibited. Such emotions $\square$ as jealousy, sullenness, and tempers are exhibited as often as before operation, but usually with less " kick" in them. They do not persist and " are all over in a moment", as one patient said.

There is a lowered threshold of tolerance for such $\overrightarrow{\vec{D}}$ irritations as noise, interruptions, or sudden social demands such as the unexpected arrival of visitors, and also for interpersonal friction and disagreement. These are probably reflections of the greater freedom in expressing their feelings which these patients generally show. On the other hand, in full-blown arguments subjects have usually shown a less $\vec{\circ}$ marked reaction than before operation : the initial emotional response is not sustained. Often there has been a damping down of drive and decisiveness, but this comes out only on special occasions with special demands and not in the daily planning of life's routine. There is none of the lazy solitude objectionable sullenness, or egocentricity which occasionally dominates the picture after leucotomxp The capacity for humour has not been impaired $\frac{?}{\mathrm{~T}}$ 음 in fact, there are examples of considerably more healthy reaction to joking and ribald activities.

In social intercourse there is greater mobility ang freedom of expression, and often a greater forts rightness in behaviour. But there is never reckles. $\vec{c}$ or impulsive action of the kind resulting from lack of normal foresight, as may be seen after a frontal leucotomy. Nor is there any lack of reasonable care or thoroughness or any display of overtly unkind or unsympathetic behaviour. There is a loss of pathological worrying and introspection ; and on the affective side also there is a marked loss of timidity and selfconsciousness.

This expansion of social activity is not evident where there was probably none at all in the past. But where, before operation, social expression was obviously inhibited or distorted by illness or constrictive personality traits, it is afterwards seen in a fuller, more vigorous fashion. There seems to be a greater flexibility and play in talking, laughing, and all the minor manifestations of self-expression in everyday social intercourse.

It has also been observed that the subjects will talk more quickly and directly on topics normally requiring a period of "warming-up". They may more readily discuss the character deficiencies of their friends, and are more willing to talk on closely personal matters or details of sex life. They show a $N$ greater apparent willingness to expose their feelings. 
There has been a constant reduction in the intensity of morbid anxiety, but without any pathological impairment of the normal capacity for healthy worrying and sympathetic concern. There has always been a lessening in the perseveration of obsessional thoughts and fears : the automatic and mechanically repetitive aspect disappears. If asked directly, patients usually say that the thoughts may still occur, but they no longer trouble them and there is no difficulty in dismissing them and turning their attention to other matters. As time goes by their actual occurrence is also less frequent. The resulting improvement in the effectiveness of thought and behaviour may be striking.

It is interesting to recall that Goldstein (1936), after an extensive experience of subjects with frontal lesions more widespread than in our cases, said that at first sight they appear normal and their defects can only be revealed with special methods of examination. Since then these methods have defined the picture of frontal lobe lesions in general sufficiently for us to recognize typical changes in many such cases, even at brief interview. In contrast to this, however, patients with a cingulate lesion do not show any of the expected indications of frontal lobe deficit, and still give an impression of " normality", and only detailed study reveals the characteristic changes we have described.

If we apply these changes to the therapeutic field, those patients may be expected to benefit in whom there is a rigid, constricted personality, with exacting standards of behaviour and excessive response to environmental demands. Where the disease process itself is intrinsic to or destructive of personality, as in a schizophrenic process (Tow and Armstrong, 1953), the operation is likely to be of very little value. The fact that beneficial changes seem to occur in certain symptoms, with no adverse effect on the whole personality, suggests that the operation should have further trial in certain psychoneurotic patients whose illness is intractable and disabling.

The changes summarized above have so far been strikingly consistent. Though they may be slight, the full case histories provide much detailed and concrete exemplification. Their constancy has in our experience provided a surprising contrast with the variation of pattern seen after standard leucotomy. Essentially they take the form of a reduction of perseveration in both affective and cognitive spheres, and a general disinhibition, lacking objectionable features, and providing a freer and usually rather less integrated personality.

\section{Summary}

Changes in personality in eight undeteriorated patients following bilateral ablations in the anterior cingulate region are described. The lesions were small, $3 \mathrm{~cm}$. long and $1 \mathrm{~cm}$. wide, and great care was taken to avoid damage elsewhere. Changes were slight, but consistent : they are confined chiefly to a reduction of inhibition, perseveration, and excessive self-concern.

\section{REFERENCES}

Glees, P., Cole, J., Whitty, C. W. M., and Cairns, H. (1950). Journal of Neurclogy, Neurosurgery and Psychiatry, 13, 178 .

Goldstein, K. (1936). J. Neurol. Psychopath., 17, 27.

Smith, W. K. (1945). J. Neurophysiol., 8, 241.

Tow, P. McD., and Armstrong, R. W. (1953). J. ment. Sci. In the press.

Ward, A. A. (1948a). J. Neurophysiol., 11, 13.

1948b). The Frontal Lobes, Res. Publ. Ass. nerv. ment. Dis., $27,438$.

Whitty, C. W. M., Duffield, J. E., Tow, P. M., and Cairns, H. (1952). Lancet, 1, 475. 